Матвеева C.B.

\title{
ЭКОНОМИЧЕСКАЯ КОНЪЮНКТУРА РОССИИ 1925-1926-Х ГГ. И ОСНОВНЫЕ ПОЛОЖЕНИЯ ОПТИМИЗАЦИИ РАЗВИТИЯ ЭКОНОМИКИ СТРАНЫ ПО Н.Д. КОНДРАТЬЕВУ
}

Аннотация: В данной статье рассматривается актуальный в наше время вопрос об экономическом наследии Н.Д. Кондратьева, раскрывается проблема изучения социально-экономической концепции отечественного историка и экономиста, а именно - циклично-волновой теории Н.Д. Кондратьева, которую он разработал в рамках своей концепции социальной экономики. В статье анализируется состояние экономической конъюнктуры России 1925-1926-х г2. по Н.Д. Кондратьеву, раскрывается содержание событий экономической жизни страны в указанный период. Делается попытка представления основных положений оптимизации развития экономики страны, составленных на основе изучения научного наследия российского экономиста с мировым именем. В статье анализируется суть его концептуальной схемы, в которой ученый развивает свои взгляды на модель экономического поведения; рассматриваются его теоретические предложения по оптимизации экономического развития как научный фундамент, имеющий огромную научную изенность в формировании современной модели Российской социально-экономической системы.

Review: This article concerns a topical issue of economical heritage of N.D.Kondratiev, discussing the problem of studying social-economic concept of the Russian historian and economist, namely, cyclic wave theory of N.D. Kondratiev, which was developed by him within the framework of his concept of social economics. The article provides analysis of the economic conjuncture of Russia in 1925-1926 according to N.D. Kondratiev, revealing the contents of events of economic life of Russia at that time. The author attempts to present the main provisions of optimization of economic development of the state based upon the studies of the scientific heritage of the globally renowned Russian economist. The article provides analysis of his conceptual scheme, where the scientist develops his views upon the model of economic behavior, the author studies his theoretical proposals for the optimization of economic development, viewing it as a scientific basic of great scientific value for the formation of the modern model of social-economic system of Russia. Ключевые слова: Пропорцчиональное развитие, программа пропорционального развития, ножницьь цчен, теория длинных волн, соччиальная экономика Кондратьева, экономическое поведение, экономическая конъюнктура, равновесие рыночного механизма, оптимизации развития экономики, критерии оптимальности развития.

Keywords: Proportionate development, proportionate development program, price scissors, theory of long waves, social economics of Kondratiev, economic behavior, economic conjuncture, balance of the market mechanism, optimization of economic development, criteria for the optimum development.

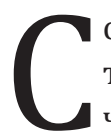
овременная социально-экономическая ситуация в России требует научно-теоретического осмысления и выбора наиболее эффективного пути ее развития. В этой связи весьма актуальным является изучение социально-экономической концепции отечественных историков, экономистов, научный потенциал которых представляет большой интерес для разработки и успешного развития отечественного экономического курса. На наш взгляд, такими свойствами обладает циклично-волновая теория Н.Д. Кондратьева, которую он разработал в рамках своей концепции социальной экономики.
Научное наследие Н.Д. Кондратьева обширно и многообразно и в этом не только проявилась разносторонность интересов ученого, но и нашла отражение сложность общественных процессов, свидетелем которых он был и к осознанию которых он стремился не как сторонний наблюдатель, а как активный участник. Ученый много сделал для разработки методологии планирования и прогнозирования экономики, путей преобразования сельского хозяйства и организации сельскохозяйственного производства, теории конъюнктуры и экономической динамики, организации научных исследований по 
целому ряду направлений. Система его взглядов, теоретических и эмпирических исследований (которая, к сожалению, не была завершена) является своеобразным синтезом отечественной и мировой экономической и социальной мысли первой четверти XX в. Кондратьев принадлежал к тем редким специалистам, которые старались выйти за узкие рамки разделения общественных наук, анализирующих экономическую жизнь современного ему общества, пытаясь построить единую концептуальную схему междисциплинарного синтеза.

Для научного творчества Кондратьева были характерны объективный подход к анализу социально-экономических событий своего времени, потребность при интерпретации социально-экономических явлений избегать всякого рода социальных мифов, желание стоять на почве фактов при оценке и прогнозе событий будущего, вера в возможности научного прогноза. Все вышесказанное объясняет интерес к научному творчеству Н.Д. Кондратьева в целом и к его работам, написанным адекватно ретроспективе экономических событий в стране, в отдельности.

Рассмотрим один из примеров конъюнктурно-экономического анализа параметров функционирования российской экономики в условиях советской власти 1924-1925 гг. ${ }^{1}$ Здесь речь идет о конкретной социально-экономической ситуации, которая связана с возникновением так называемых «ножниц цен» и их последствиях. Она, по мнению Кондратьева, является отражением наметившегося в этот период конфликта между городом и деревней, в условиях экономической политики форсированного развития промышленного производства при постоянном повышении сельскохозяйственных цен. ${ }^{2}$ Анализируя ситуацию, которая сложилась в народном хозяйстве, Кондратьев акцентирует внимание на фундаментальных факторах и социально-экономических условиях, определяющих конкретную конъюнктуру народного хозяйства в данный период.

\footnotetext{
${ }^{1}$ Кондратьев Н.Д. Современное состояние народнохозяйственной конъюнктуры в свете взаимоотношений индустрии и сельского хозяйства // Соц. хоз-во. - М., 1925. - N 6. - C.40-66.

${ }^{2}$ Там же.
}

Объективной особенностью российской экономики периода 1924-25 г.г. являлось, во-первых, возникновение двух взаимосвязанных секторов народного хозяйства. Первый -промышленный, был на 80\% национализирован и находился в непосредственном управлении государством. Второй - сельскохозяйственный, функционировал на рыночной основе и был распылен по миллионам мелких хозяйств. Оба сектора были связаны между собой через рынок, Это же касалось и отдельных отраслей промышленности. Государственная политика управления экономикой того периода заключалась в переводе всей экономики на рельсы планового регулирования и овладения стихийными силами народного хозяйства.

Кондратьев полемизировал с концепциями, объясняющими факт диспропорции между сельским хозяйством и промышленностью, во-первых, значительным превышением размера сельскохозяйственного производства и производства промышленных товаров, во-вторых, превалированием размера товарной массы сельскохозяйственной продукции по отношению к объему товарной массы промышленности. Основную причину диспропорции он видел в факторах, которые способствуют разбапансированию рынка, связывающего сельскохозяйственный и промышленный сектора народного хозяйства. Это приводит, при относительном росте промышленного и сельскохозяйственного производства, к тому, что именно на рынке, связывающем промышленность и сельское хозяйство, наблюдается усиление диспропорции цен, которая способствует, во-первых, консервации предложения сельскохозяйственной продукции со стороны крестьян в связи с низкими ценами ее на рынке. Во-вторых, - падению спроса на промышленные товары в связи с высокими ценами.

Анализируя ситуацию диспропорции промышленности и сельского хозяйства в российской экономике того периода, Кондратьев показал предпосылки достижения равновесия в условиях функционирования более сложной системы народного хозяйства, но обязательно при существовании рынка. ${ }^{3}$ Не разделяя точку зре-

\footnotetext{
3 Кондратьев Н.Д. Современное состояние народнохозяйственной конъюнктуры в свете взаимоотношений индустрии и сельского хозяйства // Соц. хоз-во. - М., 1925. - N 6. - С.40-66.
} 


\section{Политика и общество 7 (115) • 2014}

ния форсированного и диспропорционального развития народного хозяйства, Кондратьев прогнозировал иной путь российской экономики в этот период. Основные принципы его «программы» пропорционального развития российской экономики заключались в следующем. ${ }^{4}$

Темпы роста промышленного производства могут быть гораздо выше даже в условиях абсолютного преобладания сельскохозяйственного сектора при условии пропорционального обмена между промышленностью и сельским хозяйством. Не всякие темпы роста индустрии можно считать оптимальными. Они имеют свои естественные границы, которые определяются точкой нарушения равновесия всего народного хозяйства, расстройством рынка, валюты и отчуждением города и деревни. Критерием для решения поставленных вопросов следует считать именно устойчивость развития всего народного хозяйства. Лишь тот темп развития промышленности представляется целесообразным и возможным, который достаточно близко отвечает реальному накоплению, доступному для обращения его теми или иными путями (политика цен, экспортная и импортная политика и т.д.) на нужды развертывания индустрии. Всякая попытка перешагнуть эти объективные границы, искусственно форсировать рост индустрии поведет неизбежно, путем ли инфляционного процесса или иным, к разрыву индустрии и сельского хозяйства и, в конечном счете, острому потрясению самой промышленности. Основной предпосылкой здорового и быстрого развития индустрии является усиление процесса накопления во всем народном хозяйстве, здоровый и мощный рост сельского хозяйства, политика, обеспечивающая обращение доступных фондов накопления на нужды развития промышленности. И, наоборот, здоровый рост сельского хозяйства предполагает не только развитие экспорта, но и мощное развитие индустрии,

Опираясь на эти положения, Кондратьев предпринял попытку дать анализ той экономической ситуации, которая сложилась в 1924-26 г.г. в народном хозяйстве России. Следует отметить, что в этом анализе достаточно краткого периода функционирования российского (советского) на-

${ }^{4}$ Там же. родного хозяйства имманентно были заложены особенности его функционирования, которые в полной мере проявились лишь в достаточно отдаленном будущем.

Суть диспропорции и процессов, ее обусловливающих, Кондратьев видит в той экономической политике, которая способствовала кредитной экспансии. Конъюнктурный фактор кредитной экспансии, всплеск которой наблюдался в 1924 -25 г.г., Кондратьев объясняет общей тенденцией экономической политики государства на интенсификацию промышленного сектора за счет сферы потребления. Анализируя процесс кредитной экспансии в российской экономике того периода, Кондратьев выделяет следующие его особенности. Во-первых, резкое возрастание кредитов приходится на февраль месяц 1925 года. Во-вторых, синхронно этому процессу обзоры текущей конъюнктуры начинают отмечать (с февраля-марта и июля) нарастание активного спроса на рынке, который с августа начинает квалифицироваться как состояние товарного голода. В-третьих, активные кредитные операции развивались не только за счет притока средств в виде текущих счетов, вкладов и депозитов, но также за счет увеличения эмиссии новых денег.

Анализируя процессы форсированного роста промышленности в рамках периода 1924 -25 годов, Кондратьев делает следующие выводы.

1. В народном хозяйстве советской России намечается тенденция преимущественного развития промышленного сектора, производящего средства производства. Это говорит о том, что те политические силы, которые пришли к власти, отказываются от приоритетов пропорционального развития народного хозяйства за счет преимущественного инвестирования тех отраслей, которые дают эффект для потребительского сектора лишь через некоторое время.

2. Рост промышленного производства вызвал соответствующий рост числа занятых работников и заработной платы. В результате этого произошел значительный рост доходов городского населения, в соответствии с чем увеличился спрос на предметы потребления, в том числе личного. При существующей ситуации роста доходов и одновременного па- 
дения темпов роста средств потребления платежеспособный спрос городского населения не обеспечивается соответствующим предложением. Это обстоятельство способствует обострению проблемы товарного голода. Таким образом, дефицит товаров на городских рынках является одной из причин товарного дефицита для сельскохозяйственных районов. Одновременно политика понижения отпускных цен промышленных товаров, которая в целом является положительным явлением, в данной ситуации товарного голода способствует естественному возрастанию розничных цен. Они возросли (в среднем по 20 промтоварам в Москве) с $32,7 \%$ на 1 апреля 1224/25 г.г. до 56,5\% на 1 октября.

3. Следующая особенность кредитной экспансии, способствовавшей возникновению дефицита товаров на городских и сельских рынках, объясняется широкой заготовительной компанией сельскохозяйственных товаров, которая опиралась на столь же широкий план ее кредитования. Размер активных операций по финансированию хлебозаготовительной компании на 1 октября 1925 г. достиг 256,7 млн. рублей против 66,7 рублей на 1 октября 1924 г. в конечном итоге и деревне в этот же период был предъявлен огромный денежный спрос на ее продукты. ${ }^{5}$

Эти обстоятельства повлекли за собой следующие последствия: потенциальное предложение зерна со стороны сельскохозяйственных производителей существенно увеличилось, обозначилось превышение спроса над предложением на сельскохозяйственных рынках, что объясняется диспропорцией цен на промышленные и сельскохозяйственные товары, деревня на 1 октября 1925 года накопила большой объем денежных средств; при напряженном спросе на сельскохозяйственную продукцию рынок промышленных товаров для села оказался ненасыщенным в связи с их оттоком в городской сектор; платежеспособный спрос на промышленные товары

\footnotetext{
${ }^{5}$ Кондратьев Н.Д. Современное состояние народнохозяйственной конъюнктуры в свете взаимоотношений индустрии и сельского хозяйства // Соц. хоз-во. - М., 1925. - N 6. - C.40-66.
}

сельского населения существенно сдерживался, с одной стороны, в связи с их высокими ценами, a, с другой стороны - низкими ценами на сельскохозяйственную продукцию. Таким образом, у сельского населения скопилась большая денежная масса, которую нельзя было предъявить на товарном рынке в связи с низкой покупательной способностью денег. Этот сдвиг экономической мотивации крестьянских хозяйств вызвал резкий уход их с рынка в область натурального накопления, личного потребления и вынужденного резервирования. Такая реакция сельскохозяйственного сектора объясняется Кондратьевым основной особенностью российских крестьянских хозяйств. Она заключается в том, что в большинстве своем мелкие крестьянские производители (число которых в СССР достигало 22 млн.) ${ }^{6}$, даже при высокой норме товарности своей продукции, не могут выбросить ее на рынок в значительном количестве. Это объясняется следующими причин, во-первых, большим колебанием конъюнктур урожайности. Во-вторых, отсутствием у крестьянских хозяйств резервных мощностей для стабильного товарного выхода на рынок. В-третьих, низкими нормами потребления крестьянских хозяйств, которые были незначительными еще до революции и существенно уменьшились в 20-х годах,

Естественно, что всякое излишнее экономическое давление на мелких производителей существенно разрушало их связь с рынком, тем более что сам рынок в этих условиях находился на грани разрушения и замещался централизованными методами координации. Далее, «сжатие» рынка сельскохозяйственной продукции в период 1925 г. объяснялось и тем, что форсированное разрушение рыночных механизмов, способствовало возникновению не только «товарного голода», но и голода в прямом смысле этого слова. Из вышесказанного стоит выделить наиболее существенные особенности экономической ситуации, которая сложилась в системе рыночных отношений между городом и деревней в период 1924-26 гг.

\footnotetext{
${ }^{6}$ Кондратьев Н.Д. Современное состояние народнохозяйственной конъюнктуры в свете взаимоотношений индустрии и сельского хозяйства // Соц. хоз-во. - М., 1925. - N 6. - C.40-66.
} 


\section{Политика и общество 7 (115) • 2014}

1. Кредитная экспансия, являясь следствием экономической политики преимущественно развития промышленного сектора, вызвала целый ряд дисфункций в рыночном и распределительном механизмах и способствовала созданию диспропорций между промышленным и сельскохозяйственным секторами.

2. Интенсивный рост инвестиций в промышленность через механизмы кредитования способствовал росту промышленного производства и в особенности средств производства. Это привело к повышению занятости и росту покупательной способности городского населения относительно сельского. В результате чего возникли, во-первых, диспропорция между спросом и предложением готовых изделий, во-вторых, напряженный спрос на сельскохозяйственные товары. То есть при относительном росте промышленного и сельскохозяйственного производства возник дефицит и на промышленные и на сельскохозяйственные товары.

3. Наличие относительного избытка денег в обращении не обеспечивалось их покупательной способностью, в связи с чем возникла ситуация, при которой, при относительном росте предложения промышленных и сельскохозяйственных товаров, спрос на эти товары на всех рынках возрастал в соответствии с падением покупательной силы денег.

4. В результате возникновения отложенного спроса, не обеспеченного платежными средствами и непропорционального роста цен промышленной продукции относительно продукции сельскохозяйственной, образовались серьезные диспропорции между городом и деревней и так называемый товарный голод (дефицит).

Эту экономическую ситуацию Кондратьев пытался объяснить двояким образом. В первом случае, он, используя схему Маркса, доказывает своим оппонентам экономическую нецелесообразность форсированных методов развития российского народного хозяйства и «производства ради производства». ${ }^{7}$ Во вто-

\footnotetext{
7 Эту аргументацию Кондратьева в рамках схемы расширенного воспроизводства развивают В. Симонов и Н. Фигуровская, См.: Симонов В., Фигуровская Н. Послесловие
}

ром случае, свою систему аргументации Кондратьева строит на основе анализа механизмов «кредитной экспансии», рассматривая две гипотетические макроэкономические ситуации. В рамках одной возможно сохранение рыночного равновесия между промышленностью и сельским хозяйством, в рамках другой возникает диспропорция.

Таким образом, можно заключить следующее. Равновесие рыночного механизма спроса и предложения между двумя важнейшими секторами российского народного хозяйства в 20-х годах было нарушено вмешательством государства. Последнее сознательно способствовало сохранению «ножниц цен», датируя промышленность и ограничивая рыночный спрос и предложение со стороны сельского хозяйства. Всякая же «подкачка» спроса в этих условиях за счет эмиссии денег приведет к неизбежной инфляции.

В условиях российской экономики 20-х годов сдерживание инфляции и ее социальноэкономических последствий, при искусственно форсируемой диспропорции индустриального и аграрного секторов, осуществлялось методами внеэкономического принуждения. В результате этого основная масса частных крестьянских хозяйств постепенно выводилась из рыночного оборота и в обстановке тотального насилия переводилась на рельсы коллективизации. Естественно, что все мероприятия советского правительства по уничтожению элементов рыночной экономики в деревне реализовывались сознательно, а та ситуация, которую наблюдал Кондратьев, являлась конкретным результатом этой политики, способствовавшей непропорциональному перераспределению экономических ресурсов между городом и деревней в соответствии с идеологическими установками правящего режима.

Кондратьев, прекрасно понимая неэффективность плановой экономики и предпринял попытку (правда, безуспешную) с помощью научных аргументов показать возможность развития пропорционального и оптимального развития народного хозяйства России в этих

к прогнозу: Кондратьевские циклы и Россия/ Особое мнение 2 т. - М.: Наука,1993, с. 503-506. 
условиях. В этой связи весьма интересна его аргументация относительно возможностей и критериев «равновесного» или пропорционального развития народного хозяйства. Оно составляют суть его теоретической полемики относительно направлений экономической политики в этот период.

\section{Основные положения оптимизации развития экономики страны по Н.Д. Кондратьеву}

Главный тезис аргументов Кондратьева заключается в следующем. В условиях 20-х годов при данном положении народного хозяйства оптимальным можно считать то соотношение темпов роста индустрии и сельского хозяйства, которое, во-первых, обеспечивает бескризисное развитие экономики. Во-вторых, обеспечивает наибольший рост реального народного дохода. В-третьих, гарантирует получение скорейшего эффекта от вложения средств в народное хозяйство. В-четвертых, дает возможность приложения труда относительного наибольшего количества населения. ${ }^{8}$

Эти четыре критерия оптимального развития российской экономики должны, по мнению Кондратьева, быть взяты в сочетании и строгой координации друг с другом. ${ }^{9}$ Рассматривая структуру и соотношение этих критериев для конкретных условий развития российской экономики, Кондратьев формулирует вариант теории динамического равновесия для экономики того периода. Она носит не только теоретический, но и прикладной характер и может быть взята, по его мнению, за основу экономической политики «бескризисного развития».

Первый критерий оптимальности. Первое условие реализации этого критерия. Темпы роста вложений в производство капитальных благ должны соответствовать размерам реальных сбережений страны как государственных, так и частных. То есть расширение производства средств производства всегда означает выделение соответствующей доли реальных благ на цели

\footnotetext{
${ }^{8}$ Кондратьев Н.Д. Индустрии и сельское хозяйство в их взаимоотношении / Особое мнение. 2т. - М.: Наука, 1993, c. $351-373$.

${ }^{9}$ Кондратьев Н.Д. Указ. соч., с. 366.
}

не личного, а производственно-хозяйственного характера. При данном уровне развития производства готовых товаров спрос на них будет покрыт соответствующим товарным предложением лишь в том случае, если имеется примерно такая же сумма сбережений, которая не используется в потребительском секторе, а идет на инвестиции производства.

В конечном случае речь идет о пропорциональном расширении производства капитальных благ, которое соответствует объему сбережений. Нарушение этого условия способствует возникновению цепной реакции следующих «дисфункций» в сфере обращения - товарный рынок теряет равновесие, возникает дефицит товарной массы, цены обнаруживают тенденцию к росту, покупательная сила денег понижается, а банковские вклады изымаются.

Второе условие. Поддержание пропорций между темпом роста производства средств производства и средств потребления, при соответствующей роли импортно-экспортных отношений для сохранения этой пропорции. В случае отрицательного баланса средств потребления их недостающее предложение может быть покрыто за счет импорта, а в случае положительного баланса средств потребления их избыток на внутреннем рынке может быть уменьшен за счет экспорта.

Третье условие. Между развитием производства, работающего на сельскохозяйственном сырье, внутренними производителями этого сырья и другими отраслями промышленного производства должна поддерживаться соответствующая пропорция. В случае ее нарушения в сторону уменьшения внутреннего производства сырья его недостаток должен пополняться импортом и наоборот.

Четвертое условие. Необходимость сохранения соответствия между принятым темпом роста индустрии и темпом роста производства предметов потребления в сельском хозяйстве. При нарушении баланса между производством сельскохозяйственного и индустриального секторов, его восстановление должно быть обеспечено взвешенной экспортно-импортной политикой. Нарушение этого баланса грозит следующими кризисными последствиями. В первом случае основные затруднения падут на промышленность, кото- 


\section{Политика и общество 7 (115) • 2014}

рая не сможет, по словам Кондратьева, осуществлять своего расширения. Во втором случае, если возникает избыток сельскохозяйственной продукции, и он не будет поглощаться экспортом, то рано или поздно наступит «девальвация» сельскохозяйственных товаров.

Пятое условие. Обеспечение соответствия между размерами роста промышленности и сельского хозяйства и оборотом экспортно-импортных операций. В данном случае Кондратьев акцентирует внимание на двух аспектах этой проблемы:

- $\quad$ оптимальное функционирование российской экономики невозможно в условиях изоляции от мирового рынка и международного разделения труда;

- $\quad$ сбалансированное развитие экономик отдельных государств, особенно при возрастающих темпах роста базовых отраслей невозможно при отсутствии соответствующих этому темпу объемов экспортно-импортного обмена.

Второй критерий оптимального соотношения темпов развития индустрии и сельского хозяйства - обеспечение максимального прироста реального народного (национального) дохода, возможного при данных объективных условиях. Кондратьев акцентирует внимание на следующих направлениях, которые позволяют решать эту задачу:

1. Должен соблюдаться принцип приоритетных вложений в те отрасли, которые дадут наибольшую отдачу.

2. Одновременное развитие многих отраслей с разным уровнем производительности и отдачи повышает совокупные издержки и понижает прирост реального национального дохода.

3. Ускорение темпа роста индустриальных и сельскохозяйственных производительных сил, особенно экономик, находящихся на этапе аграрного перенаселения, требует тщательного выбора приоритетных отраслей, вложения в которые при данных естественных и хозяйственных условиях могут дать наибольший прирост реального народного (национального) дохода.

4. Последнее требование тем настоятельнее, чем беднее страна, чем меньше ее накопление и чем большее значение имеет для нее высокий темп роста национального дохода.
Третий критерий оптимального соотношения темпов развития различных отраслей народного хозяйства - обеспечение быстрейшего экономического эффекта от затрат средств (инвестиций) в те или иные отрасли народного хозяйства. Он в наибольшей степени касается тех стран, в которых имеет место низкий уровень накопления, и которые поэтому нуждаются в быстром хозяйственном эффекте от производимых затрат. Естественно, что реализация экономической политики в соответствии с этим критерием возможна при учете эффективности капитальных вложений и заинтересованности государства и общества в скорости получения этого эффекта.

Четвертый критерий оптимального соотношения темпов развития различных отраслей народного хозяйства как раз соответствует условиям российской экономики того периода. Он сформулирован Кондратьевым следующим образом. Чем более страна перенасыщена рабочей силой и чем менее она насыщена капиталом, тем интенсивнее она должна обеспечить занятость для большего числа населения, Таким образом, политика занятости в соответствии с вышеуказанным критерием должна, при прочих равных условиях, быть направлена на максимальное вовлечение трудоспособного населения в различные формы занятости и пропорциональное распределение потоков занятости в полной координации с критериями, описанными выше.

Помимо вышеперечисленных критериев и способов их реализации Кондратьев формулирует дополнительный критерий правильного соответствия цен индустриальных и сельскохозяйственных товаров. ${ }^{10}$ Это такое соответствие цен, которое должно обеспечить, при данных условиях, необходимый уровень накопления для дальнейшего расширенного воспроизводства и индустрии, и сельского хозяйства. Применительно к условиям российской экономики $20-$ х годов оптимальный баланс цен промышленных и сельскохозяйственных товаров нарушается в связи c чрезвычайной дороговизной промышленного производства и торгового аппарата, который

${ }^{10}$ Кондратьев Н.Д. Аграрное перенаселение и уровень развития производительных сил сельского хозяйства $\mathrm{CCCP//}$ Oсобое мнение. 2т. - М.: Наука, 1993, с. 330-351. 
обеспечивает рыночный обмен между этими отраслями. Кондратьев приводит соответствующие примеры нарушения этого соответствия (равновесия), во-первых, сопоставляя уровень мировых и российских цен на промышленные и сельскохозяйственные товары и, во-вторых, рассматривая динамику индекса цен этих товаров на внутреннем рынке.

В заключении можно констатировать следующее. Критерии оптимальности, которые сформулировал Кондратьев, являлись прямым доказательством его отрицательного отношения к социально-экономической политике правящего режима, который осуществлял ее с помощью неэкономических методов, связанных с разрушением основ рыночной российской экономики и механического перераспределения имеющихся человеческих и экономических ресурсов в рамках известной идеологической схемы. Кондратьев в своем анализе взаимодействия промышленного и сельскохозяйственного сектора в России в середине 20-х годов XX века смог предвидеть те основные особенности классической социалистической экономики, которые начали проявляться уже на ранних этапах ее развития. Достаточно рассмотреть несоответствие процессов развития российской экономики того периода тем критериям, которые он выдвинул.

\section{Библиография:}

1. РГАЭ Ф. 478. Оп. 1. Д. 202, Д. 276, Д. 498, Д. 613, Д. 710, Д. 716, Д. 1091, Д. 1123, Д. 1209, Д. 1544, Д. 1549, Д. 1557, Д. 2372.

2. РГАЭ Ф. 478. Оп. 2. Д. 91, Д. 143, Д. 145, Д. 168, Д. 179, Д. 180, Д. 206, Д. 262, Д. 273, Д. 276, Д. 339, Д. 346, Д. 2143.

3. Вайнштейн А.Л. Обложение и платежи крестьянства в довоенное и революционное время / С предисл. Н.Д.Кондратьева. - М., 1924. - 157 с. 2.Вопросы конъюнктуры / Под ред. Н.Д.Кондратьева. - М.: Фин. изд-во НКФ СССР, 1925. - Т.1, вып.1-4. 203 с.

4. Давыдов Ю. Н. Д. Кондратьев и вероятностностатистическая философия социальных наук // Кондратьев Н.Д. Основные проблемы экономической статики и динамики. М,, 1991, с. 453-524.
5. Кондратьев Н.Д. Большие циклы конъюнктуры // Вопросы конъюнктуры. - М., 1925. - Т.1, вып.1. - С.28-79.

6. Кондратьев Н.Д. Большие циклы конъюнктуры: Доклады и их обсуждение в Институте экономики. М., 1928.288 с. (Рос. ассоц. н. - и. интов обществ, наук. Ин-т экономики).

7. Кондратьев Н.Д. Заключительное слово Н.Д. Кондратьева // Пути сел. Хоз-ва. М., 1926. №3.

8. Кондратьев Н.Д. К вопросу о дифференциации деревни // Пути сел. хоз-ва. - М., 1927. - N 5. С.123-140.

9. Кондратьев Н.Д. К вопросу о понятиях экономической статики, динамики и конъюнктуры // Соц. хоз-во. - М., 1924. - Кн.2. - С.349-372.

10. Кондратьев Н.Д. О крупно-крестьянских хозяйствах. Особое мнение. Книга 1 и 2. М.: Наука, 1993.

11. Конъюнктура народного хозяйства СССР и мирового в 1925-26 гг.: (Сб. обзоров по важнейшим отраслям конъюнктуры нар. хоз-ва и мирового в 1925-26 гг.) / Под ред. Н.Д.Кондратьева. - М.: Фин. изд-во НКФ СССР, 1927. - 256 с.: табл.

12. Абалкин Л.И. Научное наследие Н.Д. Кондратьева и современность // Вопросы экономики, 1992, № 10. С.4-17.

13. Авагян ГЛ., Агабекян Р.Л., Баяндурян Г.Л. История российской экономической мысли: социальная экономика Н.Д. Кондратьева: Учебное пособие. М.: Экономиста, 2007. 328 с.

14. Авагян, Г.Л. Социальная экономика Н.Д.Кондратьева / Моск. пед. гос. ун-т. - М.: Прометей, 2003. - 394 с.

15. Аукуционек СП. О теориях неравномерности экономического прогресса// Экономика и математические методы. 1986, т. ХХИ. Вып. 5, c. 797-811,

16. Бабинцев В.С., Блинков В.М. Длинные волны экономической конъюнктуры и их влияние на инновационную восприимчивость производства: Препр. / ВНИИ систем. исслед. - М.: ВНИИСИ, 1991. - 57 с. - Библиогр.: с.56-57.

17. Глазьев СЮ. Экономическая теория технического развития. М.: Наука, 1990, с 230.

18. Глинка М.С. Современные мысли, или пророки в своем Отечестве., Ленинград, 1989.

19. Кондратьев Н.Д. Большие циклы конъюнктуры и теория предвидения. Избранные труды / Н.Д. 


\section{Политика и общество 7 (115) • 2014}

Кондра حтьев; Международный фонд Н.Д. Кондратьева и др.; Ред. колл.: Л.И. Абалкин (пред.) и др.; Сост. Ю.В. Яковец. М.: ЗАО «Издательство «Экономика», 2002. 767 с.

20. Кондратьев Н.Д. Избранные сочинения / Ред. колл. Л.И. Абалкин и др.; Сост. В.М. Бондаренко, В.В. Иванов, С.Л. Комлев и др. М.: Экономика, 1993. 543 с.

21. Кондратьев Н.Д. Основные проблемы экономической статики и динамики: Предвар. эскиз / Подгот. В.В.Иванов, М.С.Ковалева; АН СССР. Ин-т социологии; Комис. по науч. наследию Н.Д.Кондратьева. - М.: Наука, 1991. - 570 с.

22. Кондратьев Н.Д. Особое мнение: Избр. произведения в 2-х кн. / Рос. акад. наук. Ин-т экономики, Междунар. фонд Н.Д.Кондратьева. В 2 книгах. М.: Наука, 1993. 1 кн. - 655 с., 2 книга с.719.

23. Нельсон Р., Уинтер С. Эволюционная теория экономических изменений. М.: ЗАО «ФИНСТАТФОРМ», 2000. с.474. Ш.Никитин С. Теории длинных волн и научно-технический прогресс // МЭ и МО, 1986,№8,с.101-110.

24. Симонов, В.В.; Фигуровская, Н.К Экономика здравого смысла : Штрихи к портрету Н.Д. Кондратьева // Вестн. АН СССР. - М., 1991. N 4. - С. 46-58. - Библиогр.: с. 57-58

25. Симонов, В.В.; Фигуровская, Н.К. Экономический прогресс России в трудах Н.Д. Кондратьева (к 100-летию со дня рождения) // Пробл. прогнозирования. - М., 1992. - Вып 5. - С. 5-15

26. Яковец Ю.В. Циклы. Кризисы. Прогнозы. - М.: Наука, 1999. - 448 с.

\section{References (transliteration):}

1. Davydov Yu. N. D. Kondrat'ev i veroyatnostno-statisticheskaya filosofiya sotsial'nykh nauk // Kondrat'ev N.D. Osnovnye problemy ekonomicheskoi statiki i dinamiki. M, 1991, s.453-524.

2. Kondrat'ev N.D. Bol'shie tsikly kon' 'yunktury // Voprosy kon'yunktury. - M., 1925. - T.1, vyp.1. - S.28-79.

3. Kondrat'ev N.D. Bol'shie tsikly kon' yunktury: Doklady i ikh obsuzhdenie v Institute ekonomiki. M., 1928.288 s. (Ros. assots. n. - i. in-tov obshchestv, nauk. In-t ekonomiki).

4. Kondrat'ev N.D. Zaklyuchitel'noe slovo N.D. Kondrat'eva // Puti sel. Khoz-va. M., 1926. №3.
5. Kondrat'ev N.D. $\mathrm{K}$ voprosu o differentsiatsii derevni // Puti sel. khoz-va. - M., 1927. - N 5. S.123-140.

6. Kondrat'ev N.D. K voprosu o ponyatiyakh ekonomicheskoi statiki, dinamiki i kon' 'yunktury // Sots. khoz-vo. - M., 1924. - Kn.2. - S.349-372.

7. Kondrat'ev N.D. O krupno-krest'yanskikh khozyaistvakh. Osoboe mnenie. Kniga 1 i 2. M.: Nauka, 1993.

8. Abalkin L.I. Nauchnoe nasledie N.D. Kondrat'eva i sovremennost' // Voprosy ekonomiki, 1992, № 10. S.4-17.

9. Avagyan GL., Agabekyan R.L., Bayanduryan G.L. Istoriya rossiiskoi ekonomicheskoi mysli: sotsial'naya eko $\neg$ nomika N.D. Kondrat'eva: Uchebnoe posobie. M.: Ekonomista, 2007. 328 s.

10. Avagyan, G.L. Sotsial'naya ekonomika N.D. Kondrat'eva / Mosk. ped. gos. un-t. - M.: Prometei, 2003. $-394 \mathrm{~s}$.

11. Aukutsionek SP. O teoriyakh neravnomernosti ekonomicheskogo progressa// Ekonomika i matematicheskie metody. 1986, t. KhKhI. Vyp. 5, s. 797-811,

12. Babintsev V.S., Blinkov V.M. Dlinnye volny ekonomicheskoi kon' 'yunktury i ikh vliyanie na innovatsionnuyu vospriimchivost' proizvodstva: Prepr. / VNII sistem. issled. - M.: VNIISI, 1991. - 57 s. Bibliogr.: s.56-57.

13. Glaz'ev SYu. Ekonomicheskaya teoriya tekhnicheskogo razvitiya. M.: Nauka, 1990, s 230.

14. Glinka M.S. Sovremennye mysli, ili proroki v svoem Otechestve., Leningrad, 1989.

15. Kondrat'ev N.D. Bol'shie tsikly kon'yunktury i teoriya predvideniya. Izbrannye trudy / N.D. Kondrat'ev; Mezhdunarodnyi fond N.D. Kondrat'eva i dr.; Red. koll.: L.I. Abalkin (pred.) i dr.; Sost. Yu.V. Yakovets. M.: ZAO «Izdatel'stvo «Ekonomika», 2002. $767 \mathrm{~s}$.

16. Kondrat'ev N.D. Izbrannye sochineniya / Red. koll. L.I. Abalkin i dr.; Sost. V.M. Bondarenko, V.V. Ivanov, S.L. Komlev i dr. M.: Ekonomika, 1993. $543 \mathrm{~s}$.

17. Kondrat'ev N.D. Osnovnye problemy ekonomicheskoi statiki i dinamiki: Predvar. eskiz / Podgot. V.V.Ivanov, M.S.Kovaleva; AN SSSR. In-t sotsiologii; Komis. po nauch. naslediyu N.D.Kondrat'eva. - M.: Nauka, 1991. - 570 s.

18. Kondrat'ev N.D. Osoboe mnenie: Izbr. proizvedeniya v 2-kh kn. / Ros. akad. nauk. In-t ekonomiki, 
Mezhdunar. fond N.D.Kondrat'eva. V 2 knigakh. M.: Nauka, 1993. 1 kn. - 655 s., 2 kniga s. 719.

19. Nel'son R., Uinter S. Evolyutsionnaya teoriya ekonomicheskikh izmenenii. M.: ZAO «FINSTATFORM», 2000. s.474. Sh.Nikitin S. Teorii dlinnykh voln i nauchno-tekhnicheskii progress // ME i MO, 1986,№8,s.101-110.

20. Simonov, V.V.; Figurovskaya, N.K Ekonomika zdravogo smysla : Shtrikhi k portretu N.D. Kond- rat'eva // Vestn. AN SSSR. - M., 1991. - N 4. S. 46-58. - Bibliogr.: s. 57-58

21. Simonov, V.V; Figurovskaya, N.K. Ekonomicheskii progress Rossii v trudakh N.D. Kondrat'eva (k 100-letiyu so dnya rozhdeniya) // Probl. prognozirovaniya. - M., 1992. - Vyp 5. - S. 5-15

22. Yakovets Yu.V. Tsikly. Krizisy. Prognozy. - M.: Nauka, 1999. - 448 s. 